\title{
Non-Preference / Antixenosis and Antibiosis Mechanism Contributing to BPH Resistance in Certain Identified Elite Rice Genotypes
}

\author{
M. Udayasree* and P. Rajanikanth \\ Department of Entomology, College of Agriculture, Rice Research Centre, Agricultural \\ Research Institute, Rajendranagar, PJTSAU, Hyderabad-500030, India \\ *Corresponding author
}

\begin{abstract}
A B S T R A C T

\begin{tabular}{|l|}
\hline Ke y w or d s \\
Antixenosis, BPH, \\
Honeydew excretion \\
test
\end{tabular}

The present investigation was carried out on Non-preference / Antixenosis and antibiosis mechanism contributing to BPH resistance in certain identified elite rice genotypes. Antixenosis mechanism of resistance was assessed through studies on Honey dew excretion test and fecundity test. Among all the test entries with moderate resistance, Sabita recorded lowest honeydew excreted area of $37.33 \mathrm{~mm}^{2}$ and followed by KNM 2307, KNM 2305 and PTB 33 registered significantly lower honeydew excretion (40.33, 44.33 and $50.33 \mathrm{~mm}^{2} / 5$ females, respectively). Minimum number of eggs/female were laid on three rice genotypes viz., KNM 2305 (39.33) and RNR 25838 (41.00). All the selected rice genotypes showed significantly lower total eggs/female compared to the susceptible check $\mathrm{TN}_{1}$ (159.33). Lowest hatchability was observed in KNM 2305 (54.61\%) followed by PTB33 (57.74\%) and KNM 2307 (58.46\%) than all other test cultures.
\end{abstract}

\section{Introduction}

Rice is a staple food for a large part of the world's human population, especially in East, South and Southeast Asia, making it the second most consumed cereal grain. More than 90 per cent of the world's rice is grown and consumed in Asia where 60 per cent of the global population live. It is cultivated in about 154 million hectares annually which is equivalent to 11 per cent of the world's cultivated land. India is one of the world's largest producer of rice (Oryza sativa L.), accounting for 20 per cent of world's production. Rice is affected by more than two hundred insect pests of which about a dozen are economically important (Grist and Lever, 1969). Among the several insect pests of rice, brown planthopper (BPH), Nilaparvata lugens (Stal.) is a major one which severely damages rice crop successively every year, in most of the Asian countries. BPH is widely distributed in rice growing areas throughout South and Southeast Asia.

Brown planthopper (BPH), Nilaparvata lugens (Stal.) is a sporadic pest in most of the rice growing tracts of the world. The brown planthopper, is a phloem-sap-sucking insect pest of rice (Sogawa, 1982). Feeding causes reduction in chlorophyll and protein content of leaves followed by reduced rate of 
photosynthesis, in case of severe attack, it causes extensive plant mortality referred to as 'hopper burn' symptom.

Among the various methods (cultural, use of resistant varieties, biological and chemical control) available for managing $\mathrm{BPH}$, the most commonly adopted method is the use of insecticides. The insecticides though effective, their improper and consistent large scale use causes; resurgence and insect developed resistance against insecticides thus aggravating the $\mathrm{BPH}$ problem. In recent years, $\mathrm{BPH}$ infestations have increased across Asia, causing heavy yield losses in rice. As the popular rice varieties are susceptible to planthoppers, farmers are forced to depend solely on chemical pesticides for controlling this insect, which are expensive in terms of labour, cost and also pose environmental hazards. In addition, overuse of pesticides destroy the natural predators and leads to the development of insecticidal resistance, which results in pest resurgence. The most economical and environment-friendly strategy to manage this insect is by adopting of varieties genetically resistant to $\mathrm{BPH}$.

\section{Materials and Methods}

In order to determine the extent of feeding by $\mathrm{BPH}$ on different test entries, honeydew excreted by the BPH was measured in the test entries that were found to be resistant and moderately resistant to $\mathrm{BPH}$ along with the resistant check Ptb 33 and the susceptible check TN1. The study included estimation of honeydew area excreted by constant number of insects by feeding on different germplasm accessions.

\section{Honeydew excretion}

Homopteran insects being sap feeders, suck plant sap containing large quantity of water. To prevent dilution of the digestive enzymes, excess water is sent out by filter chamber mechanism and this excretory product is called honeydew which is rich in sugars, amino acids, waxes and lipids etc. Amount of honeydew excreted indicates extent of feeding by $\mathrm{BPH}$ on different test entries along with the resistant check, PTB 33 and the susceptible check, TN1. Thus the honeydew excretion test is conducted as a means to measure the feeding preference of $\mathrm{BPH}$ towards a germplasm, based on which the level of resistance and susceptibility of a germplasm towards BPH is determined. The quantity of honeydew excreted by BPH on each of selected entry was measured by adopting the method modified by Pathak and Heinrichs (1980).

The seeds of the selected entries were soaked in plastic petri dishes separately and the germinated seeds were sown in pots. 30 day old plants were used for conducting the honeydew experiment. Whatman no.1 filter paper was taken and a small hole was made in the center of the circle with a longitudinal cut in the circle from margin to the hole. The filter paper was dipped in $0.02 \%$ bromocresol green solution dissolved in ethanol and allowed to dry for one hour. The dried filter paper was dipped again in the same solution till it turned yellowish orange. A card board sheet was taken and was cut in to square shapes of $12 \times 12 \mathrm{~cm}$ size and a hole was made in the center of the square. The stem of one month old plant was inserted through the hole and the card board square was kept at the base of the plant and the hole was plugged with nonabsorbent cotton. A polythene sheet and paper were placed on the card board to prevent moisture absorption by the filter paper. The treated filter paper circle was placed on the card board at the base of the plant. A transparent plastic cup was kept inverted over the filter paper and five adult gravid females, pre starved for four hours were released into the cup. 
The insects were allowed to feed for 24 hours at the base of the stem. The honeydew droplets excreted by the $\mathrm{BPH}$ were made to fall on the bromocresol green treated filter paper which turned into blue spots when they came in contact with bromocresol green. The filter paper was taken out and the area of the spots was measured by graph paper method. All the honeydew spots were traced on a trace paper and the trace paper was kept on a millimeter square graph paper and the numbers of squares within the spots were counted. The area of all the spots was added and the area of honeydew excretion was expressed as $\mathrm{mm}^{2}$ per five females or five nymphs. Different entries were statistically compared on the basis of mean value obtained from three replications.

Fecundity, Ovicidal test / per cent Egg hatching

Seeds of the selected test entries were soaked in petri dishes and the germinated seeds were sown in pots. When the plants were 30 days old, they were thoroughly examined and cleaned to make them free from adults and eggs of other hoppers or mirid bugs before the release of adults. They were covered with mylar tubes with ventilating windows. A pair of one day old adults were released with the help of an aspirator in the mylar cage and the open end of the tube was covered with a muslin cloth and tied with a rubber band. The adults were removed after keeping for four days,. Subsequently, the plants were carefully observed for emergence of nymphs (hatched eggs). The first instar nymphs that hatched out from the eggs deposited by the adults were recorded daily and were removed with an aspirator to avoid recounting of them on the next day. The total number of nymphs that hatched on the test plants were calculated based on the daily counts of emerged nymphs. Recording of data was done only for successive ten days, starting from the day of emergence of first nymph, the remaining eggs if any present in the plant tissue were considered as unhatched eggs. Those unhatched eggs were counted by following the method proposed by Khan and Saxena (1986).

To count the unhatched eggs, the plants containing unhatched BPH eggs were boiled in water for 5-7 minutes to coagulate the yolk of unhatched eggs and also to partially bleach the plant. The boiled plants were then kept in 95\% ethyl alcohol for three days to completely bleach the plant material. The plants were then rinsed in tap water and immersed in $1 \%$ aqueous acid fuschin solution for two days. Washing of plants under running tap water was later done till stained brown planthopper eggs were differentiated from the de-stained plant tissue. Unhatched eggs were then counted under a $5 \mathrm{X}$ binocular microscope and data was recorded. Each treatment was replicated three times.

Fecundity $=$ Number of nymphs hatched + unhatched eggs.

Number of nymphs emerged

Per cent Hatchability = -------------------- × 100

Total number of eggs laid

\section{Results and Discussion}

\section{Honeydew Excretion test}

The amount of honeydew excreted in the present study ranged from $37.33 \mathrm{~mm}^{2}$ to $266.66 \mathrm{~mm}^{2}$. The results indicated that all the resistant rice cultures showed significantly less amount of honeydew excretion as compared to susceptible check TN1 (266.66 $\mathrm{mm}^{2}$ ) (Table 1 and Fig. 1). Among all the test entries with moderate resistance, Sabita recorded lowest honeydew excreted area of $37.33 \mathrm{~mm}^{2}$ and followed by KNM 2307 , KNM 2305 and PTB 33 registered significantly lower honeydew excretion 
(40.33, 44.33 and $50.33 \mathrm{~mm}^{2} / 5$ females, respectively). The rice cultures viz., RNR 25993/2 (51.33 $\left.\mathrm{mm}^{2}\right)$, MTU 1001 (62.33 $\left.\mathrm{mm}^{2}\right)$, MTU $1010\left(66.33 \mathrm{~mm}^{2}\right)$ recorded low honeydew excretion when compared to RNR $26111\left(78.00 \mathrm{~mm}^{2}\right)$, RNR $23079\left(83.66 \mathrm{~mm}^{2}\right)$, JGL $24423\left(89.33 \mathrm{~mm}^{2}\right)$, Sinna sivappa $\left(133.00 \mathrm{~mm}^{2}\right)$ and RNR $21571\left(138.33 \mathrm{~mm}^{2}\right)$ recorded highest honeydew area among the rice cultures tested. Highest honeydew excretion $\left(266.66 \mathrm{~mm}^{2}\right)$ was recorded in susceptible check (TN1).

Kale et al., (2007) studied the antixenosis mechanism of resistance against $\mathrm{BPH}$ on 121 promising rice genotypes, among which three genotypes were found to be resistant and 20 were moderately resistant, whereas 98 genotypes were susceptible. The resistant rice genotypes had the least feeding values (24.8 to $39.0 \mathrm{~mm}^{2}$ honeydew excretion area) with the highest numbers of probes (25 to 40 per seedling) in 24 hours feeding duration with vice versa in susceptible rice genotypes. Alagar et al., (2007) reported that the amount of food intake is directly proportional to the amount of honeydew excreted by BPH. The lowest feeding rate was recorded in Ptb 33 $\left(86.3 \mathrm{~mm}^{2}\right)$, which was ten times lower than the susceptible TN1 $\left(811.3 \mathrm{~mm}^{2}\right)$. Reddy et al., (2016) studied antixenosis mechanism of resistance to brown planthopper in selected resistant, moderately resistant and moderately susceptible entries and reported less quantity of honey dew excretion (26.3- $46.3 \mathrm{~mm}^{2}$ ) in resistant cultivars compared to other cultivars.

\section{Fecundity}

The resistant and moderately resistant rice cultures, which served as hosts for BPH, had adverse effect on biology of $\mathrm{BPH}$, while the susceptible check, TN1 favoured multiplication of the pest. Resistant and moderately resistant entries were proved detrimental to $\mathrm{BPH}$. Effect of different rice entries on fecundity are presented in Table 2 and Fig 2 that indicated decrease in fecundity of BPH when fed on resistant and moderately resistant entries compared to the susceptible check, TN1.

Among the perusal of the data revealed that the hatched eggs (emerged nymphs) / female ranged from 21.66 to 87.00 . Significantly lowest nymphs were observed in moderately resistant KNM 2305, RNR 25838 and PTB33 (21.66, 27.33 and 36.00 nymphs/female, respectively) which were on par and significantly different from other test cultures.

This was followed by JGL 24423, RNR 21571, KNM 2307, RNR 26111, RNR 25993/2 and Sabita (36.66, 38.33, 39.00, 41.66, 42.66 and 44.33 nymphs/female, respectively) which were significantly lower than other test cultures. Highest number of hatched eggs were recorded in susceptible check (TN1).

Among the test cultures, the total number of $\mathrm{BPH}$ eggs/female ranged from IET 23993(30.00) to Sinna sivappa (70.66), as against the susceptible check $\mathrm{TN}_{1}$ (112.00). Significantly minimum eggs/female were laid on the rice genotypes viz., KNM 2305 (39.33) and RNR 25838 (41.00) which were on par and significantly different from other test cultures. This was followed by JGL 24423 (56.00), RNR 21571 (57.33), Sabita (59.33), RNR 25993/2 (60.00), PTB 33 (62.33), RNR 26111 (65.66) which were significantly lower than other test cultures. All the selected rice genotypes showed significantly lower total eggs/female compared to the susceptible check $\mathrm{TN}_{1}$ (159.33).

Reddy et al., (2016) reported that per cent egg hatchability was higher in susceptible check, TN $1(88.6 \%)$ and a significant reduction in the egg hatchability was noticed in resistant and moderately resistant entries. 
Table.1 The amount of honeydew excreted by BPH in different rice genotypes

\begin{tabular}{|c|c|c|}
\hline S. No. & Rice genotype & Honeydew Excretion $\left(\mathrm{mm}^{2} / 5\right.$ females $)$ \\
\hline 1. & MTU 1001 & $62.33^{\mathrm{b}}$ \\
\hline 2. & MTU 1010 & $66.33^{\mathrm{bc}}$ \\
\hline 3. & RNR 23079 & $83.67 \mathrm{c}^{\mathrm{d}}$ \\
\hline 4. & IET 23993 & $67.00^{\mathrm{bc}}$ \\
\hline 5. & JGL 24423 & $89.33^{\mathrm{cd}}$ \\
\hline 6. & SABITA & $37.33^{\mathrm{a}}$ \\
\hline 7. & KNM 2307 & $40.33^{\mathrm{ab}}$ \\
\hline $\mathbf{8 .}$ & RNR 21571 & $138.33^{\mathrm{ef}}$ \\
\hline 9. & SINNA SIVAPPA & $133.00^{\mathrm{e}}$ \\
\hline 10. & RNR 25838 & $70.33^{\mathrm{bc}}$ \\
\hline 11. & RNR 25993/2 & $51.33^{\mathrm{ab}}$ \\
\hline 12. & RNR 26111 & $78.00^{\mathrm{c}}$ \\
\hline 13. & KNM 2305 & $44.33^{\mathrm{ab}}$ \\
\hline 14. & PTB 33 & $50.33^{\mathrm{ab}}$ \\
\hline 15. & TN 1 & $266.67^{\mathrm{g}}$ \\
\hline & C.D. & 15.36 \\
\hline & SE(m) & 5.29 \\
\hline & SE(d) & 7.48 \\
\hline & C.V. & 10.75 \\
\hline
\end{tabular}

Table.2 Fecundity and Hatchability test

\begin{tabular}{|c|c|c|c|c|}
\hline S.no & Rice genotype & $\begin{array}{c}\text { Hatched Eggs (Emerged } \\
\text { nymphs)/ female }\end{array}$ & $\begin{array}{c}\text { Total Eggs/ } \\
\text { female }\end{array}$ & Hatching (\%) \\
\hline $\mathbf{1 .}$ & MTU 1001 & $47.66^{\mathrm{c}}$ & $68.33^{\mathrm{cd}}$ & $69.79^{\mathrm{bc}}(56.69)$ \\
\hline $\mathbf{2 .}$ & MTU 1010 & $50.33^{\mathrm{cd}}$ & $67.00^{\mathrm{cd}}$ & $74.84^{\mathrm{bc}}(60.03)$ \\
\hline $\mathbf{3 .}$ & RNR 23079 & $51.66^{\mathrm{cd}}$ & $74.00^{\mathrm{cd}}$ & $69.92^{\mathrm{bc}}(56.85)$ \\
\hline $\mathbf{4 .}$ & IET 23993 & $30.00^{\mathrm{b}}$ & $59.00^{\mathrm{bc}}$ & $61.01^{\mathrm{ab}}(45.56)$ \\
\hline $\mathbf{5 .}$ & JGL 24423 & $36.66^{\mathrm{bc}}$ & $56.00^{\mathrm{b}}$ & $65.55^{\mathrm{b}}(54.04)$ \\
\hline $\mathbf{6 .}$ & SABITA & $44.33^{\mathrm{bc}}$ & $59.33^{\mathrm{bc}}$ & $74.79^{\mathrm{bc}}(59.95)$ \\
\hline $\mathbf{7 .}$ & KNM 2307 & $39.00^{\mathrm{bc}}$ & $66.33^{\mathrm{c}}$ & $58.46^{\mathrm{ab}}(49.87)$ \\
\hline $\mathbf{8 .}$ & RNR 21571 & $38.33^{\mathrm{bc}}$ & $57.33^{\mathrm{bc}}$ & $68.14^{\mathrm{bc}}(55.82)$ \\
\hline $\mathbf{9 .}$ & SINNA SIVAPPA & $48.33^{\mathrm{cd}}$ & $70.66^{\mathrm{cd}}$ & $68.41^{\mathrm{bc}}(55.79)$ \\
\hline $\mathbf{1 0 .}$ & RNR 25838 & $27.33^{\mathrm{ab}}$ & $41.00^{\mathrm{ab}}$ & $66.78^{\mathrm{bc}}(54.83)$ \\
\hline $\mathbf{1 1 .}$ & RNR 25993/2 & $42.66^{\mathrm{bc}}$ & $60.00^{\mathrm{bc}}$ & $71.16^{\mathrm{bc}}(57.58)$ \\
\hline $\mathbf{1 2 .}$ & RNR 26111 & $41.66^{\mathrm{bc}}$ & $65.66^{\mathrm{bc}}$ & $63.56^{\mathrm{ab}}(52.85)$ \\
\hline $\mathbf{1 3 .}$ & KNM 2305 & $21.66^{\mathrm{a}}$ & $39.33^{\mathrm{a}}$ & $54.61^{\mathrm{a}}(47.65)$ \\
\hline $\mathbf{1 4 .}$ & PTB33 & $36.00^{\mathrm{bc}}$ & $62.33^{\mathrm{bc}}$ & $57.74^{\mathrm{ab}}(49.43)$ \\
\hline $\mathbf{1 5 .}$ & TN1 & $87.00^{\mathrm{d}}$ & $112.00^{\mathrm{d}}$ & $77.68^{\mathrm{c}}(61.81)$ \\
\hline & C.D. & 8.39 & 10.07 & 10.89 \\
\hline & SE(m) & 2.88 & 3.46 & 3.74 \\
\hline & SE(d) & 4.07 & 4.89 & 5.29 \\
\hline & C.V. & 11.40 & 9.33 & 9.64 \\
\hline
\end{tabular}

*Values in the parenthesis are angular transformed 
Fig.1 Feeding rate of BPH in different rice genotypes in terms of honeydew excretion

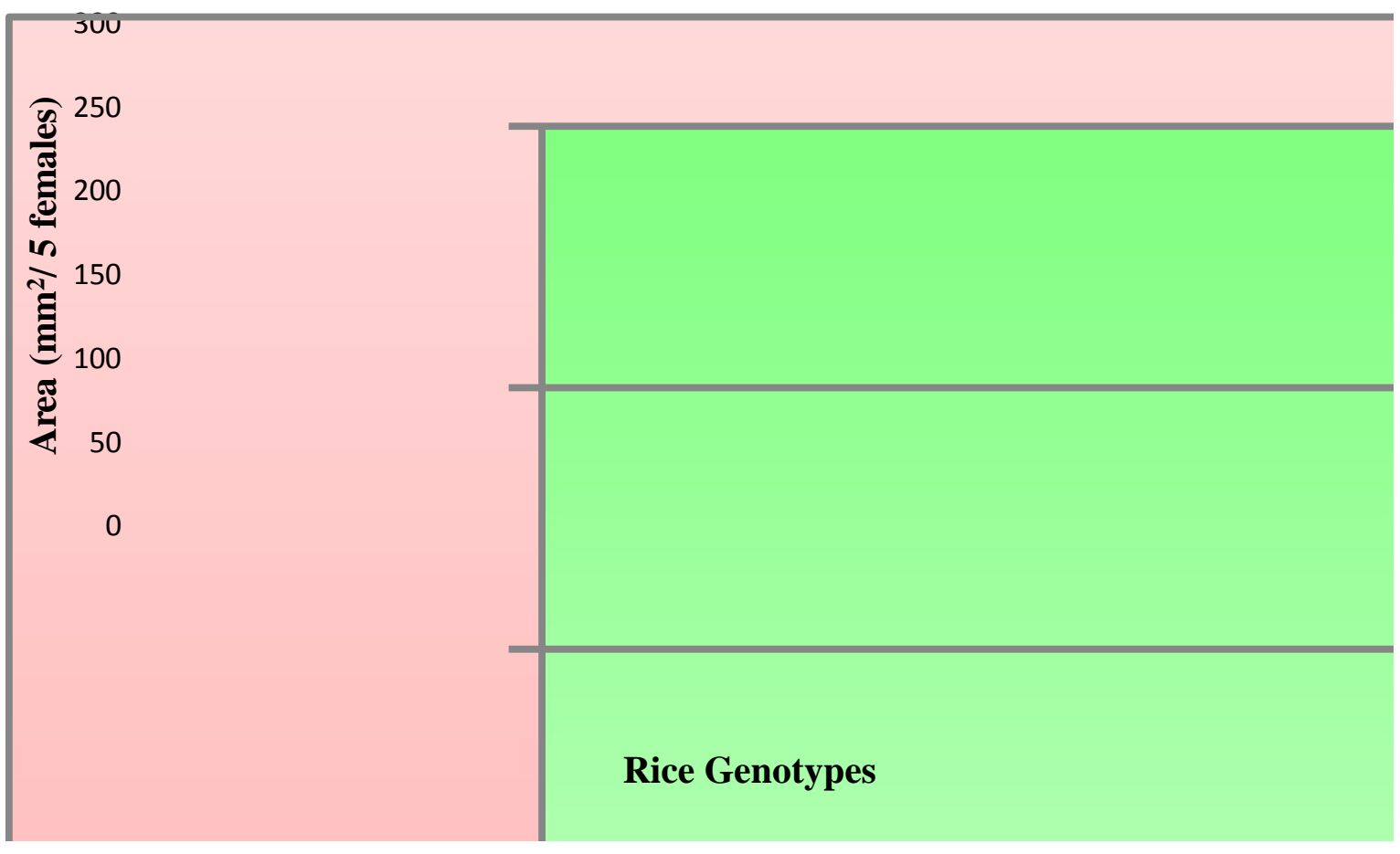

Fig.2 Fecundity and Hatchability of BPH in different rice genotypes

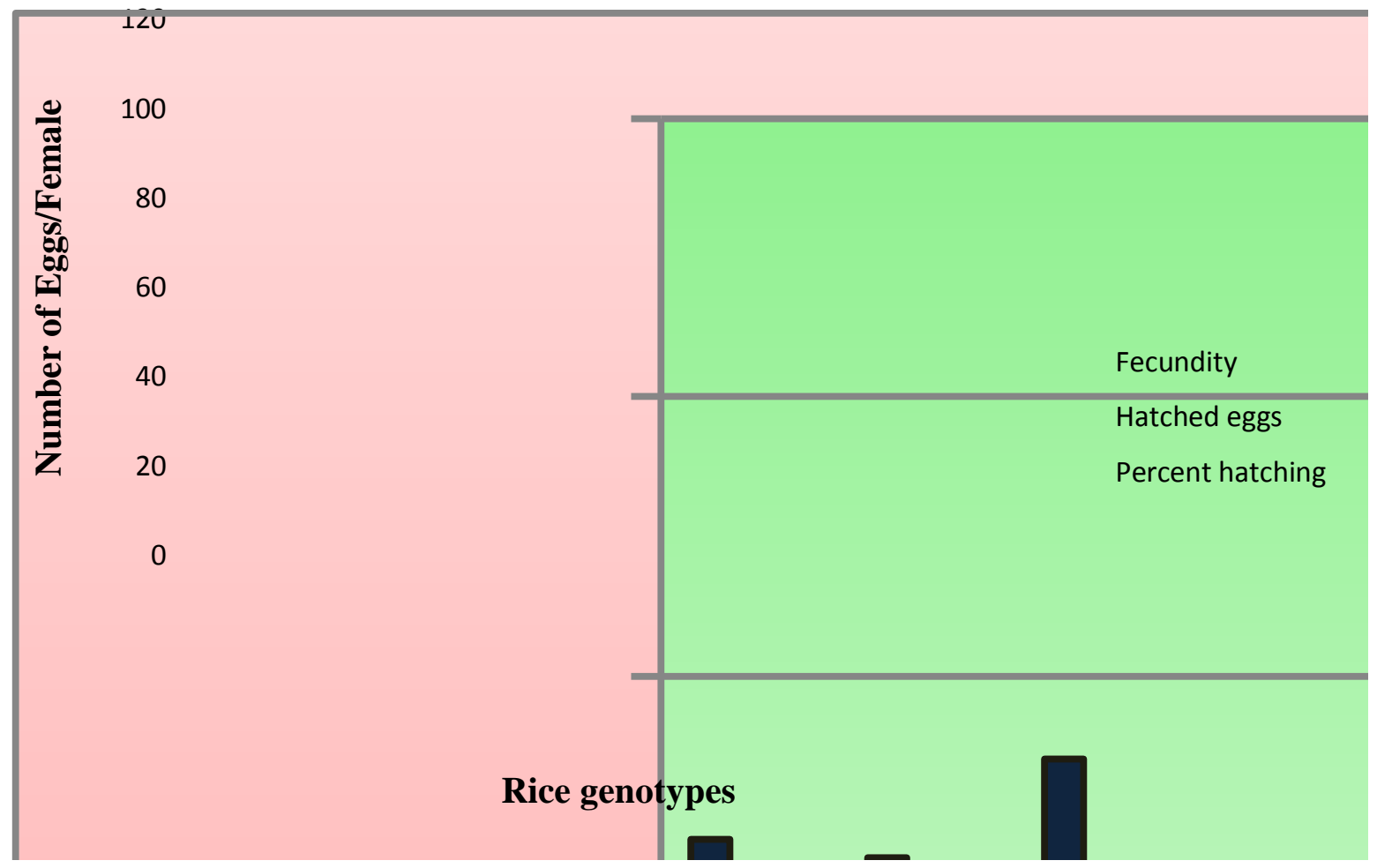


The per cent egg hatchability ranged from 28.7 (Ptb-33) to 48.5 (IET 23739); 43.5 (IET 23223) to 67.8 (IET 23696); and 65.9 (IET 23391) to 75.1 (IET 23741) on resistant, moderately resistant and moderately susceptible entries, respectively.

\section{Hatchability}

The results of study on the effect of different rice genotypes on $\mathrm{BPH}$ hatchability showed that, the per cent hatchability ranged from 54.61 to 77.68 across the test cultures and varied significantly (Table 2).

Significantly lower hatchability was observed in KNM 2305 (54.61\%) followed by PTB33 $(57.74 \%)$ and KNM 2307 (58.46\%) than all other test cultures.

This was followed by RNR 26111 (63.56\%), RNR 25838 (66.78\%), RNR 21571 (68.14\%), Sinna sivappa (68.41\%), MTU $1001(69.79 \%)$ and RNR 23079 (69.92\%) which were significantly different from each other. Significantly highest per cent hatchability was observed in MTU 1010 and $\mathrm{TN}_{1}$ with 74.84 and 77.68 , respectively.

It is evident from the perusal of overall data that, the per cent hatchability was lower in resistant and moderately resistant rice genotypes than susceptible variety.

This clearly suggests that hatching may be adversely affected due to some factors present in the resistant/moderately resistant genotypes.

\section{References}

Alagar, M and Suresh, S. 2007. Antibiosis mechanism of resistance to brown planthopper, Nilaparvata lugens (Stal.) on selected rice genotypes. Annals of Plant Protection Sciences. 15(2): 283286.

Grist, D.H and Lever, R.J.A.W. 1969. Pests of rice. Longmans, Green and Co. Ltd., London. pp. 520.

Kale, G.B., Karnewa, S.D and Dudhare, M.S. 2007. Evaluation of rice accessions for mechanism of resistance to brown planthopper (Nilaparvata lugens Stal.). New Botanist. 34 (1): 121-126.

Khan, Z.R and Saxena, R.C. 1986. Technique for Locating Planthopper (Homoptera: Delphacidae) and Leafhopper (Homoptera: Cicadellidae) Eggs in Rice Plants. Journal of Economic Entomology. 79:271-273.

Pathak, P.K and Heinrichs, E.A. 1980. A rapid technique for estimation brown planthopper feeding activity. International Rice Research Newsletter. 5: 18-19.

Reddy, B. N., Jhansi Lakshmi, V., Umamaheswari, T., Ramulamma, A and Katti, G.R. 2016. Non preference/antixenosis mechanism to brown planthopper (Nilaparvata Lugens Stal.) in selected rice entries. The Journal of Research PJTSAU. 44(1\&2): 1-10.

Sogawa, K. 1982. The rice brown planthopper: feeding physiology and host plant interactions. Annual Review of Entomology. 27(1): 49-73.

\section{How to cite this article:}

Udayasree M. and Rajanikanth P. 2018. Non-Preference / Antixenosis and Antibiosis Mechanism Contributing to BPH Resistance in Certain Identified Elite Rice Genotypes. Int.J.Curr.Microbiol.App.Sci. 7(06): 1908-1914. doi: https://doi.org/10.20546/ijcmas.2018.706.226 